\title{
The influence of repeated pain stimulation on the emotional aspect of pain: a preliminary study in healthy volunteers
}

This article was published in the following Dove Press journal:

Journal of Pain Research

23 July 2015

Number of times this article has been viewed

\section{Hiroshi Maeoka \\ Makoto Hiyamizu \\ Atsushi Matsuo \\ Shu Morioka}

Department of Physical Therapy, Faculty of Health Science, Kio University, Koryo-cho, Kitakatsuragigun, Nara, Japan
Correspondence: Hiroshi Maeoka Department of Physical Therapy, Faculty of Health Science, Kio University, 4-2-2 Umami-naka, Koryo-cho, Kitakatsuragi-gun, Nara, 635-0832, Japan $\mathrm{Tel}+8$ I 74554 I60।

Fax +8I 74554 I600

Email h.maeoka@kio.ac.jp
Purpose: Pain is a multidimensional experience with sensory-discriminative, cognitive-evaluative, and affective-motivational components. Emotional factors, such as unpleasantness or anxiety, are known to have influence on pain in humans. Repeated painful stimulation has been reported to reduce subjective pain intensity. Nevertheless, there is little evidence of the influence of such stimulation on the emotional factors of pain. The aim of this study was to evaluate the influence of repeated painful stimulation on the experience of unpleasantness and anxiety.

Materials and methods: Eight subjects (six females, two males) volunteered to participate in this study. Subjects received repeated painful stimulation for 3 consecutive days each instance lasting 6 seconds, 60 times per day, on the medial side of the forearm of the nondominant hand. We examined the following items to evaluate changes of responses to painful stimulation: pain thresholds, pain tolerance levels, pain intensities, unpleasantness, and anxiety. Furthermore, pain thresholds and pain tolerance levels were compared between different sites on the ipsilateral and contralateral forearms.

Results: No immediate or chronological changes in pain thresholds or pain tolerance levels were observed. Pain intensities were reduced significantly over the 3-day experimental period $(P<0.05)$. On the other hand, there was no great change in unpleasantness during the 3-day period. Anxiety was increased significantly after the painful stimulation compared with that without the painful stimulation and before day 1 of the stimulation $(P<0.05)$.

Conclusion: These results suggest that repeated painful stimulation may result in habituation to pain intensities but not habituation to emotional factors.

Keywords: anxiety, unpleasantness, pain intensity, habituation

\section{Introduction}

Pain usually has a strong negative affective component. The International Association for the Study of Pain proposes that pain is "an unpleasant sensory and emotional experience associated with actual or potential tissue damage, or described in terms of such damage". ${ }^{1}$ The experience of pain in humans is a multidimensional phenomenon manifesting sensory-discriminative, cognitive-evaluative, and affective-motivational components. ${ }^{2}$ The sensory-discriminative dimension identifies the location, timing, and physical characteristics of the noxious stimulation, and prompts withdrawal reflexes to prevent or limit tissue damage. The affective-motivational dimension, which is the one most closely linked with emotion, underlies the unpleasantness associated with exposure to a noxious stimulation and activates defensive behaviors, such as escape and recuperation, which enable the individual to cope with the noxious stimulation. The cognitive-evaluative dimension influences the appraisal of the meanings and 
consequences of an injury or pain. Therefore, the experience of pain is modulated by a complex set of emotional, attention, mood, environmental, and psychophysiological variables. ${ }^{3,4}$

In sensory systems, repeated stimuli elicit progressively smaller responses. This phenomenon is defined generally as "habituation". ${ }^{5}$ Habituation has been described in the blink reflex evoked by muscle electrical stimulation, ${ }^{6}$ the electroencephalogram arousal response following sudden stimulation, ${ }^{7}$ the somatosensory-evoked potential, ${ }^{8}$ and evoked potentials by painful dental stimulation and innocuous auditory stimuli in humans. ${ }^{9,10}$ Recently, repetitive painful stimulation in healthy subjects was reported to decrease pain perception over time and cause habituation. ${ }^{11,12}$ Functional imaging studies showed that habituation to pain in healthy controls is associated with increased activity in the rostral anterior cingulate cortex. ${ }^{11,13}$ Given the important role of the rostral anterior cingulate cortex in the endogenous modulation of pain, ${ }^{14,15}$ this finding suggests that habituation to pain involves central antinociceptive systems. ${ }^{12,16,17}$

The majority of past studies on habituation to pain employed pain intensities as an index of habituation. A few reports are available on the emotional aspects of repetitive painful stimulation. ${ }^{18}$ As mentioned above, pain is greatly affected by emotional factors, such as pleasantness/ unpleasantness and anxiety. Therefore, it is possible that emotional factors are intensified even though habituation to pain alleviates perceived pain. In this study, we examine the effects of repeated painful stimulation on pain intensities, as well as emotional aspects of pain.

\section{Materials and methods}

Eight university students (six females, two males) volunteered to participate in this study. Subjects' ages ranged from 20 to 21 years. The mean age \pm standard deviation of the subjects was $20.4 \pm 0.5$ years. All subjects had no history of neurological or psychiatric disease or drug abuse, no history of chronic or acute pain, and were not taking any form of analgesic, antidepressant, antianxiety, or antihypertensive medication. Subjects were asked to refrain from alcoholic beverages for 12 hours before the experiment. Given the known influence of depression on pain processing and perception, we confirmed that our subjects were not suffering from depression and only included volunteers with a normal score on the Beck Depression Inventory. The Beck Depression Inventory is a 21-item questionnaire that assesses the clinical symptoms of depression by examining feelings over the past week. The score ranges from 0 to $63 .{ }^{19}$ Score zero to nine indicate non depressed and normal mood, ten to 16 indicate mild, 17 to
20 moderate, 21 to 30 severe, and more than 30 indicate very severe depression. ${ }^{20}$ All subjects received detailed information about the experimental procedures, were free to withdraw from the study at any time, and provided written informed consent. The Ethics Committee of the Kio University (approval number H25-14) approved the protocols of the study.

Each subject was seated comfortably in a quiet room free from interruptions, with forearms rested on a cushion on a table. Subjects were asked to close their eyes and keep quiet during the painful stimulation. Basal pain sensitivity testing involved a pain threshold and pain tolerance assessment. Immediately before and after the pain stimulation procedure, pain threshold and pain tolerance were assessed using a thermal stimulator (UDH-105; Unique Medical Co, Ltd, Tokyo, Japan). Pain thresholds and pain tolerances were obtained with ramped stimuli $\left(0.5^{\circ} \mathrm{C} / \mathrm{s}\right.$ starting at a baseline of $32^{\circ} \mathrm{C}$ and with an upper limit of $50^{\circ} \mathrm{C}$ to avoid tissue injury). Measurement sites were: the proximal medial volar forearm of the nondominant hand, $10 \mathrm{~cm}$ distal from the medial epicondyle of the humerus (corresponding to dermatome Th1) (site 1); the distal medial volar forearm of the nondominant hand, $20 \mathrm{~cm}$ distal from the medial epicondyle of the humerus (dermatome Th1) (site 2); and the proximal medial volar forearm of dominant hand, at the same place as site 1 but on the opposite forearm (site 3). ${ }^{21}$ We assessed pain thresholds and pain tolerance levels three times at each site in a random order. In this study, three different sites were measured to evaluate the influences of peripheral and central components of habituation.

After each stimulation, subjects were instructed to rate the pain intensity and unpleasantness by putting a mark on a $100 \mathrm{~mm}$ horizontal visual analog scale (VAS). The minimum rating (left end of the scale) was represented as "no pain sensation" or "not at all unpleasant", whereas the maximum (right end) was designated as "most intense pain tolerable" or "most intense unpleasantness tolerable."

Anxiety was assessed using the Japanese version of the state subscale of the State-Trait Anxiety Inventory (STAI). STAI-1 and STAI-2 were developed as methods for the evaluation of the degree of anxiety. ${ }^{22}$ The STAI is a 40 -item selfreport assessment discriminating between state ( 20 items) and trait (20 items) anxiety. Whereas trait anxiety is assumed not to change over time and refers to "relatively stable individual differences in anxiety-proneness", state anxiety refers to the intensity of anxiety experienced in reaction to a specific event at a given time, assessing "feelings of apprehension, tension, nervousness, and worry". ${ }^{23}$ The subjects rate how much they feel like each statement at the time of making the response by marking a four-point scale ranging from "not at all" to "very 
much so". Scores range from 20 to 80, with higher scores indicating more anxiety. Before the experiment, all subjects were assessed for state anxiety in the usual resting condition (resting state), using the STAI.

The number and application time of pain stimuli were determined in reference to the procedure of Bingel et al. ${ }^{11}$ The pain stimulation protocol consisted of a session of heat stimuli. These stimulation sessions consisted of ten blocks of thermal stimuli, with each block containing a series of six pain stimuli (each lasting 6 seconds, interstimulus interval of 5 seconds), resulting in a total number of 60 thermal stimuli. The interblock interval was 30 seconds. Painful stimuli $\left(1^{\circ} \mathrm{C}\right.$ above the pain threshold) were applied via a thermal probe to the medial side of the nondominant forearm (site 1). The painful stimulus intensity measured on day 1 was used for all sessions.

The thermal probe was $10 \times 10 \mathrm{~mm}$ in size, and the probe was placed on one of the three possible positions on the forearm to prevent skin sensitization. On each day, pain threshold and pain tolerance were assessed immediately before and after the repeated pain stimulation procedure. The subjects received one session of painful stimulation. After each stimulation, subjects rated the perceived pain intensity and unpleasantness. Furthermore, state anxiety levels were also assessed immediately before and after one session of repeated pain stimulation. The subjects received a daily session of the same temperature of painful thermal stimulations on 3 consecutive days.

\section{Statistical analysis}

Pain thresholds and pain tolerance levels obtained at each of the three sites were averaged individually. In order to grade pain intensities and unpleasantness due to pain, we calculated the mean of the VAS values of each block. We also totaled the state anxiety scores of STAI to analyze changes of state anxiety. We compared daily pre- and poststimulation values using Student's $t$-test to verify immediate changes of pain thresholds, pain tolerance levels, and STAI. Moreover, we compared data of pain thresholds, pain tolerance levels, STAI, pain intensities, and anxiety from the 3 days, to assess chronological changes of these parameters. For analysis of statistical significance, one-way repeated measure analysis of variance (ANOVA) was used. If the analysis showed significance, post hoc comparisons were made using Tukey-Kramer multiple comparison tests. Analyses were carried out using GraphPad Prism 4.0 statistical software (GraphPad Software, Inc., San Diego, CA, USA). Statistical significance was considered as $P<0.05$.

\section{Results}

Table 1 shows the means and standard deviations of pain thresholds and pain tolerance levels obtained at each site during the 3-day experimental period. Changes of pain threshold and pain tolerance at all measurement sites did not show statistically significant differences between pre- and poststimulation sessions. Furthermore, chronological changes of pain thresholds and pain tolerance levels at all measurement sites did not show statistically significant differences between both prestimulation sessions and poststimulation sessions during the 3 days.

Results of VAS ratings for pain intensity and unpleasantness were expressed as mean \pm standard deviation. VAS ratings for pain intensity of repeated pain stimulation of day 2

Table I Pain threshold and pain tolerance

\begin{tabular}{|c|c|c|c|c|c|c|c|}
\hline \multirow[t]{2}{*}{ Sites } & \multicolumn{2}{|l|}{ Day I } & \multicolumn{2}{|l|}{ Day 2} & \multicolumn{2}{|l|}{ Day 3} & \multirow[t]{2}{*}{$P$-value } \\
\hline & Pre & Post & Pre & Post & Pre & Post & \\
\hline \multicolumn{8}{|l|}{ Threshold (degree) } \\
\hline $\begin{array}{l}\text { Proximal medial volar forearm } \\
\text { of nondominant hand (site I) }\end{array}$ & $44.9 \pm 1.6$ & $44.9 \pm 2.2$ & $44.3 \pm 2.6$ & $44.6 \pm 2.3$ & $44.6 \pm 2.0$ & $44.5 \pm 2.3$ & NS \\
\hline $\begin{array}{l}\text { Distal medial volar forearm of } \\
\text { nondominant hand (site } 2 \text { ) }\end{array}$ & $44.9 \pm 1.9$ & $44.6 \pm 1.0$ & $44.1 \pm 1.6$ & $43.8 \pm 2.2$ & $44.4 \pm 2.1$ & $44.0 \pm 1.8$ & NS \\
\hline $\begin{array}{l}\text { Proximal medial volar forearm } \\
\text { of dominant hand (site } 3 \text { ) }\end{array}$ & $44.7 \pm 1.6$ & $44.2 \pm 2.0$ & $44.3 \pm 2.1$ & $42.9 \pm 3.3$ & $44.6 \pm 2.1$ & $43.9 \pm 3.0$ & NS \\
\hline \multicolumn{8}{|l|}{ Tolerance (degree) } \\
\hline $\begin{array}{l}\text { Proximal medial volar forearm } \\
\text { of nondominant hand (site I) }\end{array}$ & $48.8 \pm 1.5$ & $49.2 \pm 1.1$ & $49.1 \pm 2.3$ & $49.2 \pm 2.0$ & $49.0 \pm 1.7$ & $49.7 \pm 1.8$ & NS \\
\hline $\begin{array}{l}\text { Distal medial volar forearm of } \\
\text { nondominant hand (site } 2 \text { ) }\end{array}$ & $48.9 \pm 1.3$ & $48.8 \pm 1.0$ & $48.6 \pm 2.2$ & $49.0 \pm 1.5$ & $49.3 \pm 1.6$ & $49.2 \pm 1.6$ & NS \\
\hline $\begin{array}{l}\text { Proximal medial volar forearm } \\
\text { of dominant hand (site } 3 \text { ) }\end{array}$ & 49. $1 \pm 2.1$ & $48.7 \pm 1.6$ & $48.8 \pm 2.6$ & $48.4 \pm 2.5$ & $49.1 \pm 2.0$ & $49.1 \pm 2.3$ & NS \\
\hline
\end{tabular}

Note: Values are expressed as mean \pm standard deviation. Abbreviation: NS, not significant. 
$(5.86 \pm 1.77)(P=0.01)$ and day $3(5.17 \pm 2.26)(P=0.02)$ were decreased significantly compared with VAS ratings for day 1 (7.11 \pm 1.83$)$ (Table 2).

VAS ratings for unpleasantness of repeated pain stimulation did not show statistically significant differences in poststimulation sessions during the 3 days $(7.14 \pm 1.64$ [day 1]; 6.03 \pm 1.36 [day 2]; and 6.29 \pm 2.07 [day 3]) (Table 2). Unpleasantness was maintained during the 3 days.

Results of state anxiety scores were expressed as mean \pm standard deviation. State anxiety scores showed statistically significant differences during the 3 days. State anxiety scores of the poststimulation sessions of day $1(51.88 \pm 10.47)$ were increased significantly compared with usual state anxiety scores $(37.13 \pm 6.36)(P=0.02)$ and prestimulation sessions of day $1(38.50 \pm 5.13)(P=0.04)$ (Figure 1). In addition, state anxiety scores of the poststimulation sessions of day 3 $(52.13 \pm 11.86)$ were increased significantly compared with usual state anxiety scores $(37.13 \pm 6.36)(P=0.01)$ and prestimulation sessions of day $1(38.50 \pm 5.13)(P=0.03)$ (Figure 1). On the other hand, state anxiety scores of the prestimulation sessions did not show statistically significant differences during the 3 days (Figure 1).

\section{Discussion}

The present study examined whether pain intensity, pain tolerance, unpleasantness, and anxiety were influenced by repeated painful stimulation. Our results showed neither immediate nor chronological changes of pain thresholds and pain tolerance levels. However, observed reductions of pain intensity in response to repeated pain stimulation over 3 days were consistent with those reported by Bingel et al. ${ }^{11}$ On the other hand, the experience of unpleasantness following repeated painful stimulation lasted for 3 days, with no significant change. Furthermore, anxiety was significantly aggravated after the stimulation compared with anxiety in the resting state and prestimulation anxiety on day 1.

With regard to subjective reports of pain intensity, recent studies showed that repeated painful stimulation in healthy subjects alleviates acute pain and causes habituation to painful stimuli. ${ }^{11,12,16}$ It is suggest that this process is in part mediated by the antinociceptive system. ${ }^{11,17}$ We also observed habituation to pain intensity in the present study. However, the pain threshold and pain tolerance level observed at the measurement sites of the ipsilateral-and contralateral sides showed no significant change. Rennefeld et al ${ }^{16}$ examined habituation to pain at sites different from stimulation sites, including the contralateral side, and reported that the degree of habituation to pain was reduced at the stimulation sites, at different sites on the ipsilateral side, and at sites on the contralateral side in order of decreasing habituation. They suggested that the predominant effect at the site of stimulation application compared with the heterotopic response decrement may result from a combination of central and peripheral effects, such as peripheral fatigue of $A \delta$ - and C-fiber nociceptors. ${ }^{24,25}$ Fatigue refers to a decrement in the response to repeated stimuli applied to the receptive field of sensory cells. Repetitive stimulation of the receptive field of a nociceptor may also induce a reduction in discharges in both A $\delta$ - and C-fiber nociceptive afferents. ${ }^{24,26}$ For this reason, it was possible that habituation to pain observed in the present study arose from the fatigue of peripheral nociceptors of $A \delta$ and $\mathrm{C}$-fibers involved in ascending pain sensation inputs.

With regard to subjective reports of unpleasantness and anxiety, the affective motivational dimension underlies the unpleasantness associated with exposure to a noxious stimulation. Our results showed that pain intensity habituated over repeated stimulation however, our results also showed that unpleasantness and anxiety were not changed. We hypothesized that emotional factors, such as unpleasantness and anxiety, would be alleviated together with a habituationassociated reduction of pain intensity. However, we obtained opposite results, which suggest that pain intensity is habituated if pain persists and that emotional factors may not be habituated for pain.

The discrepancy between the results of pain intensity and those of unpleasantness and anxiety in the present study may be due to many factors, including differences in the response circuits. Concerning this issue, Kulkarni et $\mathrm{al}^{27}$ reported that directing people to pay attention to the location of a noxious stimulation activated the lateral pain system, whereas attention

Table 2 Visual analog scale of pain intensity and unpleasantness

\begin{tabular}{|c|c|c|c|c|c|c|}
\hline & \multirow[t]{2}{*}{ Day I } & \multirow[t]{2}{*}{ Day 2} & \multirow[t]{2}{*}{ Day 3} & \multicolumn{3}{|l|}{$P$-value } \\
\hline & & & & Day I vs day 2 & Day I vs day 3 & Day 2 vs day 3 \\
\hline Pain intensity & $7.11 \pm 1.83$ & $5.86 \pm 1.77^{*}$ & $5.17 \pm 2.26 *$ & $P=0.01$ & $P=0.02$ & NS \\
\hline Unpleasantness & $7.14 \pm 1.64$ & $6.03 \pm 1.36$ & $6.29 \pm 2.07$ & NS & NS & NS \\
\hline
\end{tabular}

Notes: Values are expressed as mean \pm standard deviation. $* P<0.05$ vs pain intensity of day I.

Abbreviations: NS, not significant; vs, versus. 


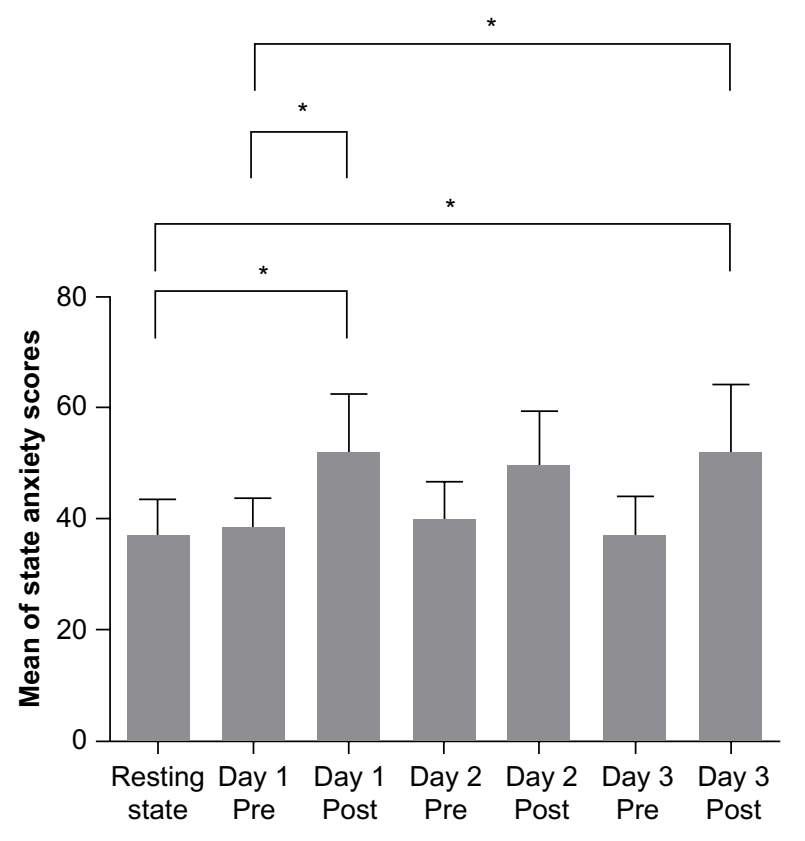

Figure I Score of the State-Trait Anxiety Inventory scale.

Notes: Data error bars display the standard error. $* P<0.05$. Resting state is described as the usual resting condition.

to the unpleasantness of the noxious stimulation activated the medial pain system. Damage to the lateral pain system makes it difficult to localize or describe the physical characteristics of pain; however, an unpleasant experience persists. ${ }^{28}$ Thus, it is suggested that primary circuits involved in pain intensity differ from those involved in emotion. Habituation to pain in relation to emotion has been reported, using pain sensation during the presentation of pleasantness-, unpleasantness-, or neutrality-provoking images. During and in between the images, suprathreshold electrocutaneous stimuli were delivered to evoke pain, the nociceptive flexion reflex, and a painevoked skin conductance response. Within-subject changes in pain responses were influenced by stimulation repetition and emotional valence.

However, habituation/sensitization slopes were unaffected by emotional valence. These results suggest that the circuit responsible for emotional modulation of pain is less susceptible to habituation or sensitization. ${ }^{29}$ In other words, emotional pain is hardly influenced by habituation to pain or by sensitization. In the present study as well, we observed no relationship between a habituation-induced reduction of pain intensity and anxiety as an emotional factor. Moreover, Ushida et $\mathrm{al}^{30}$ reported that all subjects, who experienced gentle pricks to the right palm, felt unpleasant when watching a video that depicted real pricks. These authors concluded that the experience of pain caused memory retrieval of unpleasant experiences, which is possibly related to empathy for pain.
Therefore, it is possible that learning sustained anxiety or unpleasantness influences the chronicity of pain by affecting the medial pain pathway.

Habituation is a general, nonspecific phenomenon. However, with respect to pain processing, there may be additional benefits. Clearly, one benefit is the immediate pain relief for the individual. Another benefit is that the ability to habituate to injuries and daily aches and pains may be a protective factor against the development of chronic pain. However, we have often experienced that even for a weak pain, when the pain continues, we feel strong discomfort. Emotional factors, such as unpleasantness and anxiety, may continue to exist as long as a subject is exposed to persistent pain of a milder degree. Mood and emotional state have a significant impact on the resultant pain perception and ability to cope. For example, it is a common clinical and experimental observation that being anxious about pain can exacerbate the pain experienced. ${ }^{31}$ Therefore, when we assess the pain condition, it is suggested that we should assess the emotional aspect of pain continuously if the pain is reduced, and we should provide a continuous psychosocial support.

This study has some limitations. First, in the present study, unpleasantness and anxiety were assessed subjectively by VAS and STAI. We did not verify other emotional factors in this study. Pain is affected by various emotional factors. Therefore, other psychological measures need to be investigated. Furthermore, a more objective examination of changes of emotional factors requires the assessment of physiological indicators of the autonomic nervous system, including skin conductance levels and heart rates. Second, in the assessment of pain intensity, there was no examination of cerebral or other neurological functions representative of sensory aspects of pain, or anxiety and unpleasantness representative of emotional aspects of pain. Third, sex differences were not examined in the current study. Sex differences should influence the effects of repeated pain stimulation since reports suggest that women have lower thresholds and tolerance for pain than men. ${ }^{32}$ Finally, our study sample size was small. Pain is an unpleasant sensation, and it is always subjective and emotional. Therefore, pain can be highly influenced by the individual's psychological state or by environmental factors. Further studies with a larger sample size are needed to clarify the relationship between pain intensity and anxiety in habituation to pain.

\section{Conclusion}

From the results of this preliminary study, we cannot make conclusions about the relationships between pain intensity and anxiety in habituation to pain or the possible mecha- 
nisms responsible for our findings. However, we cannot rule out the possibility that emotional factors may not be habituated.

This preliminary study provides information on habituation to repeated painful stimulation in healthy controls. Our results showed that repetitive painful stimulation induced habituation to pain intensity, a sensory aspect of pain, but unpleasantness and anxiety, which are emotional aspects of pain, may not be influenced by such stimulation. Additional studies and an increased number of subjects are needed to clarify the long-term effects of such stimulation.

\section{Disclosure}

The authors report no conflicts of interest in this work.

\section{References}

1. Merskey H, Bogduk N; Task Task Force on Taxonomy of the International Association for the Study of Pain. Classification of Chronic Pain. Descriptions of Chronic Pain Syndromes and Definitions of Pain Terms. 2nd ed. Seattle, WA: International Association for the Study of Pain Press; 1994.

2. Melzack R, Casey KL. Sensory, motivational and central control determinants of pain. In: Kenshalo DR, editor. The Skin Senses. Springfield, IL: Charles C Thomas; 1968:423-439.

3. Rainville P. Brain mechanisms of pain affect and pain modulation. Curr Opin Neurobiol. 2002;12(2):195-204.

4. Villemure C, Bushnell MC. Cognitive modulation of pain: how do attention and emotion influence pain processing? Pain. 2002;95(3): 195-199.

5. Glaser EM. The Physiological Basis of Habituation. London: Oxford University Press; 1966.

6. Duranti R, Galletti R, Pantaleo T. Relationships between characteristics of electrical stimulation, muscle pain and blink responses in man. Electroencephalogr Clin Neurophysiol. 1983;55(6):637-644.

7. Thompson RF, Spencer WA. Habituation: a model phenomenon for the study of neuronal substrates of behavior. Psychol Rev. 1966;73(1): $16-43$.

8. Jacobson RC, Chapman CR, Gerlach R. Stimulus intensity and inter-stimulus interval effects on pain-related cerebral potentials. Electroencephalogr Clin Neurophysiol. 1985;62(5):352-363.

9. Chapman CR, Colpitts YH, Mayeno JK, Gagliardi GJ. Rate of stimulus repetition changes evoked potential amplitude: dental and auditory modalities compared. Exp Brain Res. 1981;43(3-4):246-252.

10. Ohman A, Lader M. Selective attention and "habituation" of the auditory averaged evoked response in humans. Physiol Behav. 1972;8(1): $79-85$.

11. Bingel U, Schoell E, Herken W, Büchel C, May A. Habituation to painful stimulation involves the antinociceptive system. Pain. 2007; 131(1-2):21-30.

12. Teutsch S, Herken W, Bingel U, Schoell E, May A. Changes in brain gray matter due to repetitive painful stimulation. Neuroimage. 2008;42(2):845-849.

Journal of Pain Research

\section{Publish your work in this journal}

The Journal of Pain Research is an international, peer-reviewed, open access, online journal that welcomes laboratory and clinical findings in the fields of pain research and the prevention and management of pain. Original research, reviews, symposium reports, hypothesis formation and commentaries are all considered for publication.

Submit your manuscript here: http://www.dovepress.com/journal-of-pain-research-journal
13. Bingel U, Herken W, Teutsch S, May A. Habituation to painful stimulation involves the antinociceptive system - a 1-year follow-up of 10 participants. Pain. 2008;140(2):393-394.

14. Bingel U, Lorenz J, Schoell E, Weiller C, Büchel C. Mechanisms of placebo analgesia: rACC recruitment of a subcortical antinociceptive network. Pain. 2006;120(1-2):8-15.

15. Petrovic P, Kalso E, Petersson KM, Ingvar M. Placebo and opioid analgesia - imaging a shared neuronal network. Science. 2002;295(5560): 1737-1740.

16. Rennefeld C, Wiech K, Schoell ED, Lorenz J, Bingel U. Habituation to pain: further support for a central component. Pain. 2010;148(3): 503-508.

17. Riedl V, Valet M, Wöller A, et al. Repeated pain induces adaptations of intrinsic brain activity to reflect past and predict future pain. Neuroimage. 2011;57(1):206-213.

18. Breimhorst M, Hondrich M, Rebhorn C, May A, Birklein F. Sensory and sympathetic correlates of heat pain sensitization and habituation in men and women. Eur J Pain. 2012;16(9):1281-1292.

19. Beck AT, Ward CH, Mendelson M, Mock J, Erbaugh J. An inventory for measuring depression. Arch Gen Psychiatry. 1961;4:561-571.

20. Ghassemzadeh H, Mojtabai R, Karamghadiri N, Ebrahimkhani N. Psychometric properties of a Persian-language version of the Beck Depression Inventory - Second edition: BDI-II-PERSIAN. Depression and anxiety. 2005;21:185-192.

21. Foerster O. The dermatones in man. Brain. 1933;56:1-39.

22. Spielberger CD, Gorsuch RL, Lushene RE. The state-trait anxiety inventory: test manual. Palo Alto, CA: Consulting Psychologists Press; 1970.

23. Spielberger CD. (1983). Manual for the state-trait anxiety inventory (Form Y). Palo Alto, CA: Consulting Psychologists Press; 1983.

24. Peng YB, Ringkamp M, Meyer RA, Campbell JN. Fatigue and paradoxical enhancement of heat response in C-fiber nociceptors from crossmodal excitation. $J$ Neurosci. 2003;23(11):4766-4774.

25. Treede RD, Meyer RA, Campbell JN. Myelinated mechanically insensitive afferents from monkey hairy skin: heat-response properties. J Neurophysiol. 1998;80(3):1082-1093.

26. Treede RD. Peripheral acute pain mechanisms. Ann Med. 1995;27(2): 213-216.

27. Kulkarni B, Bentley DE, Elliott R, et al. Attention to pain localization and unpleasantness discriminates the functions of the medial and lateral pain systems. Eur J Neurosci. 2005;21(11):3133-3142.

28. Ploner M, Freund HJ, Schnitzler A. Pain affect without pain sensation in a patient with a postcentral lesion. Pain. 1999;81(1-2):211-214.

29. Rhudy JL, Bartley EJ, Williams AE. Habituation, sensitization, and emotional valence modulation of pain responses. Pain. 2010;148(2): 320-327.

30. Ushida T, Ikemoto T, Tanaka S, et al. Virtual needle pain stimuli activates cortical representation of emotions in normal volunteers. Neurosci Lett. 2008;439(1):7-12.

31. Ploghaus A, Narain C, Beckmann CF, et al. Exacerbation of pain by anxiety is associated with activity in a hippocampal network. J Neurosci. 2001;21(24):9896-9903.

32. Fillingim RB, King CD, Ribeiro-Dasilva MC, Rahim-Williams B, Riley JL 3rd. Sex, gender, and pain: a review of recent clinical and experimental findings. J Pain. 2009;10(5):447-485.

The manuscript management system is completely online and includes a very quick and fair peer-review system, which is all easy to use. Visit http://www.dovepress.com/testimonials.php to read real quotes from published authors. 